\title{
A CRITICAL REVIEW OF RECENT TRENDS IN BASIC AND SECONDARY SCHOOLS ENROLMENTS IN GHANA
}

\author{
H. M. Yusif a and I. Yussof ${ }^{\mathrm{b}}$ \\ ${ }^{a}$ Kwame Nkrumah University of Science \& Technology, Ghana \\ ${ }^{b}$ Universiti Kebangsaan Malaysia, Malaysia
}

\begin{abstract}
With data covering the period from 2001 to 2008, this paper investigates trends in enrolments for primary schools, junior high schools (JHS) and senior high schools (SHS) in Ghana. First, we discovered that at the primary level, the significant educational development in the last two decades covered the North and the South equally. Gross enrolment ratio (GER) was 95.7\% for the North compared with $95.8 \%$ for the South in the 2007/2008 academic year. Second, we found that at the JHS and SHS levels though the North has achieved significant growth, the enrolment gap between the North and South has not been narrowed. GER figures for JHS and SHS are $67.4 \%$ and $22 \%$ respectively for the North compared with $81.2 \%$ and $33.3 \%$ for the South. However, regional educational attainment Gini coefficients computed showed that in the 2007/2008 academic year educational attainment distribution in the North was more equitable than in the South. This is an indication of dramatic improvement of education opportunities in that part of the country.
\end{abstract}

Keywords: Education, gross enrolment ratio, net enrolment ratio, Gini coefficient, inequality, Ghana government

\section{INTRODUCTION}

This study is about issues of equity in school participation rate in Ghana from 2001 to 2008. Researchers in history have reported that King John of Portugal commanded his representatives in Elmina in 1529 to provide reading, writing and religious teaching to Africans. This marked the beginning of formal education in Ghana. Yet, it was about 380 years after the introduction of formal education at the coast that the first government primary school, the Tamale School, was established in Northern
Ghana in 1909. Primary education was then extended to other towns in the North. Primary education reached Gambaga in 1912, Wa in 1917, Lawra in 1919 and Salaga in 1923. As at 1944 , there was only one middle school serving all the Northern Territories. The number of children in primary and middle schools in the North increased from 2,218 in 1945 to 23,340 in 1957 . This figure was about $10 \%$ of children of school going age compared with $60 \%$ of children in the South who were in school (McWilliam and Kwamena-Po, 1975). 
The three northern regions have comparatively lower attendance rates for all school going ages (Ghana Statistical Service, 2008). This development might be explained by multiple factors including the following. First, a large proportion of parents could not afford the costs of education (tuition fees, textbooks, exercise books, school uniforms, etc). Second, many parents in the North were not willing to send their children to school for fear of losing their services in the farm and at home. Third, of the over 4,418 Islamic schools (Makaranta), attended mainly by Northerners, only 1,418 are recognized by the Ghana Education Service under the Islamic Education Unit (Boyle et al., 2007). This reduces the number of northerners in recognized schools (Yusif, 2009).

Consequently, Ghana has become a divided society where people in the North were predominantly associated with illiteracy and poverty. In 2005/2006, the three regions in the North contributed $70.3 \%$ of national poverty, using a poverty line of 370.89 GHC (Ghana Statistical Service, 2007). Undoubtedly, educational inequity in Ghana is a moral issue; a challenge to fairness or justice in a society in which education is the major public instrument for 'leveling the playing field' (Levin et al., 2007). Education is usually considered as the main vehicle for the promotion of social equality and social mobility (Brown, 2006; Tsakloglou \& Cholezas, 2005). It is also an economic issue since poor education leads to large social costs in the form of lower societal income and economic growth, lower tax revenues, higher costs of public services such as health and criminal justice (Levin et al., 2007).

Nkrumah's government recognized these inequalities and within the framework of social justice, pupils in the North were exempted from paying school fees and in addition text books provided free for them. Automatic scholarship schemes for students of Northern descent in the secondary schools were instituted. Nkrumah's government committed itself firmly to addressing these past inequities (McWilliam and Kwamena-Po, 1975; Yusif, 2009).
The fact is several educational reforms and educational policy documents, laws and reports have been enacted and approved from time to time to ensure that there is equity in the distribution of education in the country. These include the Education Act of 1961, the Dzobo Report 1973, the Evans Anform Committee 1986, the Education Reform Programme $1987 / 88$, inter alia.

The goal of this paper is to assess the extent to which enrolment in basic and secondary education in Ghana has spread to cover all the ten regions in the country between the 2001/2002 and 2007/2008 academic years. The study covers primary education, junior high school (JHS) education and senior high school (SHS) education. Our inability to cover tertiary institutions is due to very scarce data on enrolment based on region of origin of students, especially in the universities. Pre-primary education is also excluded because it was recently made part of formal education and many parents were yet to embrace it. In the 2007/2008 academic year the gross enrolment ratio for crèche and nursery was only $7 \%$ compared with $95 \%$ for primary school (Ministry of Education, Science and Sports, 2008).

Undoubtedly, this study is of important policy implication for the country since it has been reported that African governments often devote more attention to secondary and higher levels of education than achieving basic education (Schultz, 1999). Donors and international financial institutions have argued that such a pattern of spending, which provides large amounts of support to a restricted group of beneficiaries rather than broad equality of opportunity at a basic level, does not constitute a prudent use of scarce public resources (Deininger, 2003). However, it seems that in Ghana there has been some re-orientation towards basic education with the introduction of the capitation grant, school feeding programme and other education policies within the last two decades. It appears that not much is known about the extent to which such policies have influenced a fair distribution of education in the 


\section{Yusif and Yussof}

country, especially the stock of the country's human capital. It is important for issues of efficiency and accessibility to be addressed sufficiently if sustained growth and development is to be achieved in the country.

\section{Overview of education policies and reforms in Ghana}

Human capital has been found to be more important today than in the past (Hilmer, 2001). Therefore, in Ghana top priority has been given to the improvement in education since independence in 1957 by the Nkrumah's government. Unfortunately, it appears the numerous coup d'etats which characterized the country between 1966 and 1982 had some negative effects on the rate of education development. Education development plans initiated by previous governments were in most cases abandoned. According to McWilliam and Kwamena -Po (1975) in 1966 total enrolment into public primary schools declined by one-third in the North of Ghana.

Since 1983 there has been significant improvement in political stability, consequently education policies have emphasized improvement at all levels, right from preschool to the university. This is to enable the government of Ghana meet the challenges of economic growth and development.

Indeed, since the British colonial government's Accelerated Development Plan for Education in 1951, several educational reforms and educational policy documents, laws and reports have been enacted and approved from time to time to meet the educational needs and aspirations of Ghanaians. A few of these acts, reports and reforms are highlighted in the paragraphs that follow.

\section{The Education Act of 1961}

Before independence, education in Ghana was controlled by ordinances. These were the 1925 Southern and Ashanti Ordinances as well as the 1927 Upper and Northern Region Ordinance. However, after independence the Nkrumah's government initiated the Education Act of
1961. It was this act that laid the first uniform education policy for the whole country. The 1961 Act made very significant effort at reducing discriminatory tendencies that characterized parts of the early education system. The measures taken included the following: First, all children of school going age (6 years) were to be found places in school until the maximum school going age. This gave a legal effect of making schooling compulsory. Second, section 22 states inter alia, that 'no person shall be refused admission as a pupil to, or refused attendance as a pupil at, any school on account of the religious persuasion, nationality, race, or language of himself or of either of his parents (McWilliam and Kwamena-Po, 1975).

In summary, it can be deduced that the 1961 Act laid a firm foundation for a national system of education in Ghana that is devoid of discrimination. Again, the Act made it officially mandatory for children of school going age to go to school.

\section{The 1973 Dzobo Committee Report}

In 1970 the Dzobo committee was created to look into the structure and quality of education in Ghana. The Committee proposed the new concept of the Junior Secondary School (JSS) and Senior Secondary School (SSS) educational structure. This educational structure was to replace the old education structure. The Dzobo Committee recommendations were due to operate in 1975 but could not be implemented due to financial difficulties at that time.

In 1986 the Evans Anform Committee was set up to review the Dzobo Committee report. Subsequently, in September 1987, the reviewed Dzobo Committee report of education, a 6-3-34 format, i.e. six years of primary education, three years of JHS, three years of SHS and four years of university education was implemented. This new educational structure thus replaced the old educational system which had six years of primary school, four years of middle school, seven years of secondary education (of which five years was for the Ordinary Level Certificate and two years for the Advance 
Level Certificate) and three years of university education (Attuahene, 2006).

In summary, the Dzobo committee and the Evans Anfom committee reports cut down the number of years spent in the primary and secondary schools significantly from 17 to 12 years.

\section{The Education Reform Programme of 1987/ 88}

The 1980s witnessed many education reforms which touched on all the levels of education in Ghana. The Evans Anform Committee review among others improved enrollment at the basic and secondary education levels. It is estimated that in 1990-91 about 1.8 million pupils were attending over 9,300 primary schools with 609,000 pupils enrolled in about 5,200 junior secondary schools while 200,000 pupils were enrolled in some 250 senior secondary schools (Attuahene, 2006).

Based on improvement in access at the basic and secondary levels, it became technically necessary to also improve access at the tertiary level. But, the state of tertiary institutions was deplorable as they were characterized by low staff recruitment and retention, poor moral, decline in academic standards, and regular interruptions in the academic calendar through students and staff strikes and demonstrations (Attuahene, 2006). The University Rationalization Committee (URC) was established to undertake a broad review of post-secondary education (Ministry of Education, 2000) which led to the White Paper on tertiary education that redefined higher education to include universities, polytechnics, teacher training colleges and nursing training colleges. Thus, higher education comprises all-formal education beyond the senior high school level.

The major objective of the Tertiary Education Reforms in the late 1980s was to expand access, improve quality teaching and learning and provide the much-needed infrastructural base for accelerated technical manpower delivery for sustainable economic development. These objectives were in consonance with the policy goals of the Government of Ghana concerning higher education summarized as follows:

- To increase access to higher education

- To ensure that low and high income students, girls and boys, rural dwellers and urban dwellers all have access to quality higher education

- To improve efficient use of the scarce national resources allocated to higher education.

- To reduce reliance of public universities on central government for funding by encouraging internally generated funds.

In summary, the URC recommendations undoubtedly led to a transformation of the education system with considerable improvement in access, quality of teaching and learning, infrastructure delivery as well as management efficiency.

Since the 1990s there has been rapid expansion of education in Ghana. The number of public universities has more than doubled from three in 1990 to eight by 2009; private universities which numbered seven in 2001 are forty eight by 2009 . There are ten polytechnics, thirty eight public teacher training colleges, fourteen public nursing training colleges and 646 SHSs (153 private and 493 public). In the 2007/2008 academic year there were 657 nursery schools, 11,140 kindergartens, 13,247 primary schools and 7,423 JHS. In all these 4,041,977 pupils were enrolled. The question that needs to be addressed is, has this significant increment benefitted all regions in the country equally?

\section{Trends in Enrolments for Basic and Secon- dary Education}

The aim of this trend analysis is to find out whether the significant achievements in education development in Ghana have narrowed the enrolment gap between the North and the South. To do this gross enrolment rates (GERs) and net enrolment rates (NERs) were extracted from the Report on Basic Statistics and Planning Parameters for Basic Education in Ghana 2007/2008. This report is part of the Education Management Information System (EMIS) Pro- 


\section{Yusif and Yussof}

ject launched in January 1997 by the Ministry of Education. The data on enrolment parameters have been upgraded and also relatively more recent than those of the first and second phases of the project. The data were collected by the Ministry in collaboration with the UNESCO Institute for Statistics in March, 2008 and cover the period from 2001 to 2008. Tables 1 to 6 report data for these seven academic years (2001/2002 to 2007/2008). Data were not available for the years preceding the 2001/2002 academic year.

The choice of gross enrolment ratio (GER) and net enrolment ratio (NER) is due to the fact that these indicators present information about the coverage of child population at a particular level of education. GER is defined as a statistical measure that gives total enrolment at an education level irrespective of age as a percentage to the corresponding school age population. NER is a statistical measure which gives total enrolment at an educational level of the official age group as percentage to the corresponding school age population (Mehta, 2003). Clearly, overaged and underaged children are excluded in NER computation.

\section{Analysis of primary school enrolment}

Table 1 reports GER and Table 2 reports NER. Table 1 indicates that in the 2001/2002 academic year the three northern regions; Northern, Upper East and Upper West regions had the lowest GERs of $65 \%, 70 \%$ and $63 \%$ respec- tively. Upper East which had the highest GER among the three northern regions that year was about $7 \%$ below the lowest in the rest of the regions, i.e. Ashanti region with $77 \%$. However, in the 2002/2003 academic year, all the regions in the South had a decline in their GERs, except the three northern regions. Northern region had a marginal increase from $65 \%$ to $65.6 \%$, Upper East increased from $70 \%$ to $74.7 \%$ while Upper West increased from $63 \%$ to $68.9 \%$. In the $2005 / 2006$ academic year Upper East and Upper West regions had GERs that exceeded Ashanti, Eastern, Greater Accra, Volta and Western regions. In fact, Upper West had GER of $100.4 \%$. Only Central region had a figure exceeding the Upper West.

One significant observation is that for three consecutive academic years i.e. 2005/2006, 2006/2007 and 2007/2008 the Central region had GER exceeding 100\%. The Upper West region also had GER exceeding $100 \%$ in the $2005 / 2006$ academic year. The GER is expressed as a percentage of total enrolment regardless of age at school level ' $i$ ' in year' $t$ ' by the population in that age group 'a' which officially correspond to that level ' $i$ '. Thus, to calculate the GER at primary level, total enrolment in primary one to six, irrespective of ages, is considered which is then divided by the corresponding eligible official school age population, i.e. 6-11 years, to obtain GER. Therefore, GER exceeding $100 \%$ in the two regions might be due to two factors. First, significant number

Table 1: Gross Enrolment Rate, Primary Schools

\begin{tabular}{lccccccc}
\hline \multirow{2}{*}{ REGION } & $\mathbf{2 0 0 1 / 0 2}$ & $\mathbf{2 0 0 2 / 0 3}$ & $\mathbf{2 0 0 3 / 0 4}$ & $\mathbf{2 0 0 4 / 0 5}$ & $\mathbf{2 0 0 5 / 0 6}$ & $\mathbf{2 0 0 6 / 0 7}$ & $\mathbf{2 0 0 7 / 0 8}$ \\
\hline Ashanti & 77 & 74.0 & 76.8 & 83.2 & 84.5 & 88.9 & 92.0 \\
Brong Ahafo & 83 & 80.0 & 79.8 & 85.2 & 92.7 & 94.3 & 98.3 \\
Central & 93 & 87.3 & 88.6 & 93.7 & 101.7 & 106.8 & 108.8 \\
Eastern & 91 & 88.4 & 87.4 & 88.2 & 86.0 & 91.5 & 95.8 \\
Greater Accra & 83 & 64.2 & 75.5 & 80.3 & 71.1 & 81.0 & 87.7 \\
Northern & 65 & 65.6 & 66.8 & 71.5 & 83.6 & 87.4 & 92.1 \\
Upper East & 70 & 74.7 & 76.2 & 80.4 & 90.6 & 92.1 & 96.9 \\
Upper West & 63 & 68.9 & 71.5 & 77.3 & 100.4 & 90.5 & 98.1 \\
Volta & 83 & 75.5 & 79.1 & 81.8 & 85.6 & 86.8 & 89.7 \\
Western & 84 & 77.7 & 79.7 & 87.2 & 86.6 & 94.4 & 98.7 \\
\hline
\end{tabular}

Source: Ministry of Education EMIS Report, March 2008

Journal of Science and Technology @ KNUST April 2010 
of overaged and underaged children might enroll. Second, in locations with small population, a slight over reporting of enrolment may result into GER more than hundred (Mehta, 2003).

The NER is presented in Table 2. The data indicate that in the academic years 2001/2002, $2002 / 2003$ and 2003/2004 the three northern regions, i.e. Northern, Upper East and Upper West, had the lowest NER of less than $50 \%$. In the 2005/2006 academic year the NER gap between the northern regions and the other regions had been bridged. For example Upper West region had NER of $70 \%$ compared with $67.3 \%$ for Eastern and $67.2 \%$ for Volta. In the subsequent years there was no significant difference between the North and some of the regions in the South. What is significant is that the Central region has been recording the highest NER figure during the period under study, recording $99.4 \%$ in the $2007 / 2008$ academic year.

Indeed, from Tables 1 and 2 there do not appear to be any significant difference in GER and NER between all the ten regions in Ghana since the 2005/2006 academic year. This seems to suggest that at the primary school level, educational development has covered all the regions fairly equally.

To sum up, it should be noted that enrollment of all children of age 6-11 years will not necessarily guarantee universal primary enrolment in
Ghana. Some children enrolled will not attend regularly and this may result in high drop out rate or poor academic performance.

\section{Analysis of junior high school enrolment}

The next level to be analyzed is the JHS enrolment. The yearly GER and NER are indicated in Tables 3 and 4. The GER figures as reported in Table 3 appear to show significant gap between the three northern regions and the other regions in Ghana. The highest GER for the three northern regions in 2001/2002 was $45 \%$ in the Upper West. This is $15 \%$ lower than the lowest GER in the rest of the regions, i.e. the Brong Ahafo region with $60 \%$. This significant gap might be explained by many factors but the single most important factor might be the dominance of severe poverty in the North. However, the data reveal that only the three northern regions had significant increase in the GER in the 2002/2003 academic year. In the Ashanti, Central, Greater Accra, Volta and Western regions there was a decline while in the Brong Ahafo it was constant. The data again show that between 2002/2003 and 2007/2008, the Central region recorded the largest GER figure, reaching $95.3 \%$ in 2007/2008/ while the Upper East, recorded the lowest (i.e. 63.1\%). The relatively very low figure for the Upper East might be due to the ethnic conflict going on in the region.

Table 2: Net Enrolment Rate, Primary School

\begin{tabular}{lccccccc}
\hline \multirow{2}{*}{ REGION } & $\mathbf{2 0 0 1 / 0 2}$ & $\mathbf{2 0 0 2 / 0 3}$ & $\mathbf{2 0 0 3 / 0 4}$ & $\mathbf{2 0 0 4 / 0 5}$ & $\mathbf{2 0 0 5 / 0 6}$ & $\mathbf{2 0 0 6 / 0 7}$ & $\mathbf{2 0 0 7 / 0 8}$ \\
\hline Ashanti & 59 & 57.0 & 56.2 & 61.5 & 70.3 & 78.9 & 83.2 \\
Brong Ahafo & 59 & 58.3 & 54.2 & 57.4 & 77.3 & 82.3 & 87.5 \\
Central & 70 & 65.9 & 62.7 & 66.5 & 82.6 & 96.9 & 99.4 \\
Eastern & 67 & 66.6 & 61.5 & 61.7 & 67.3 & 80.1 & 83.9 \\
Greater Accra & 61 & 48.2 & 53.7 & 56.5 & 52.1 & 74.5 & 80.0 \\
Northern & 48 & 45.3 & 49.0 & 52.4 & 65.4 & 67.5 & 71.8 \\
Upper East & 52 & 52.0 & 53.2 & 55.5 & 67.0 & 72.8 & 77.7 \\
Upper West & 45 & 47.3 & 49.7 & 54.5 & 70.0 & 70.1 & 77.2 \\
Volta & 56 & 53.0 & 51.2 & 53.4 & 67.2 & 73.7 & 77.9 \\
Western & 64 & 58.9 & 59.2 & 65.4 & 73.3 & 83.1 & 86.6 \\
\hline
\end{tabular}

Source: Ministry of Education EMIS Report, March 2008 


\section{Yusif and Yussof}

Table 3 again indicates that from the academic year 2001/2002 to $2007 / 2008$ the three northern regions had percentage increase in GER that exceeded regions in the South. Percentage increase in GER was $27.4 \%, 24.1 \%$ and $27.7 \%$ for the Northern, Upper East and Upper West regions respectively. In the South, Western and Central regions had the highest increase of $20.8 \%$ and $20.3 \%$ respectively. Greater Accra and Volta regions had the lowest of $2.4 \%$ and $5.9 \%$ respectively.

Table 4 shows that at the JHS level NER in the three northern regions, though rising, are still below the rest of the regions in the South. In the 2001/2002 academic year, all three regions in the North each had NER of $14 \%$. This figure is about $10 \%$ lower than the region with the lowest NER in the South. In terms of percentage increase in NER between 2001/2002 2007/2008, the Upper West region had the highest, $34.3 \%$. The two remaining regions in the North, Northern and Upper East, had 26.5\% and $24.2 \%$ respectively. In the South, the Central region gained the highest of $32.8 \%$ whilst Greater Accra had the lowest of $10.3 \%$. Indeed, it appears educational expansion at the JHS level during the period under study benefitted the North more than the South.

As a consequence, by the 2007/2008 academic year the gap between the North and the South had been narrowed just that there existed wide gap between the region with lowest NER i.e. Upper East (38.2\%) in the North and the region with the highest NER, Central (69.8\%) in the South.

Table 3: Gross Enrolment Rate, JHS

\begin{tabular}{lccccccc}
\hline \multirow{2}{*}{ REGION } & $\mathbf{2 0 0 1 / 0 2}$ & $\mathbf{2 0 0 2 / 0 3}$ & $\mathbf{2 0 0 3 / 0 4}$ & $\mathbf{2 0 0 4 / 0 5}$ & $\mathbf{2 0 0 5 / 0 6}$ & $\mathbf{2 0 0 6 / 0 7}$ & $\mathbf{2 0 0 7 / 0 8}$ \\
\hline Ashanti & 67 & 66.0 & 69 & 73.8 & 75.0 & 79.5 & 82.2 \\
Brong Ahafo & 60 & 60.0 & 60.6 & 65.1 & 69.3 & 72.4 & 74.8 \\
Central & 75 & 74.4 & 76.0 & 83.0 & 86.2 & 91.9 & 95.3 \\
Eastern & 69 & 69.4 & 69.7 & 71.1 & 67.6 & 73.0 & 77.1 \\
Greater Accra & 79 & 74.1 & 74.7 & 79.3 & 69.9 & 77.2 & 81.4 \\
Northern & 39 & 42.5 & 45.4 & 51.4 & 57.5 & 59.0 & 66.4 \\
Upper East & 39 & 42.8 & 46.7 & 51.5 & 54.4 & 57.7 & 63.1 \\
Upper West & 45 & 47.0 & 50.3 & 59.6 & 67.6 & 65.2 & 72.7 \\
Volta & 68 & 66.5 & 67.8 & 69.6 & 71.9 & 70.8 & 73.9 \\
Western & 63 & 58.6 & 64.3 & 70.7 & 70.4 & 79.5 & 83.8 \\
\hline
\end{tabular}

Source: Ministry of Education EMIS Report, March 2008

Table 4: Net Enrolment Rate, JHS

\begin{tabular}{lccccccc}
\hline \multirow{2}{*}{ REGION } & \multicolumn{7}{c}{ Net Enrolment Rates in \% } \\
& $\mathbf{2 0 0 1 / 0 2}$ & $\mathbf{2 0 0 2 / 0 3}$ & $\mathbf{2 0 0 3 / 0 4}$ & $\mathbf{2 0 0 4 / 0 5}$ & $\mathbf{2 0 0 5 / 0 6}$ & $\mathbf{2 0 0 6 / 0 7}$ & $\mathbf{2 0 0 7 / 0 8}$ \\
\hline Ashanti & 36 & 42.5 & 34.9 & 38.2 & 41.6 & 53.6 & 54.4 \\
Brong Ahafo & 24 & 34.4 & 22.2 & 23.6 & 39.8 & 50.7 & 53.2 \\
Central & 37 & 45.0 & 35.3 & 37.1 & 65.0 & 67.0 & 69.8 \\
Eastern & 33 & 41.2 & 31.1 & 31.6 & 37.6 & 50.6 & 52.1 \\
Greater Accra & 43 & 44.4 & 40.7 & 42.8 & 50.0 & 51.3 & 53.3 \\
Northern & 14 & 22.4 & 16.7 & 19.2 & 24.5 & 35.1 & 40.5 \\
Upper East & 14 & 19.1 & 15.4 & 15.4 & 24.5 & 36.6 & 38.2 \\
Upper West & 14 & 21.9 & 14.9 & 17.4 & 28.0 & 41.4 & 48.3 \\
Volta & 26 & 32.2 & 24.8 & 26.0 & 43.4 & 50.0 & 50.9 \\
Western & 29 & 34.8 & 29.1 & 32.6 & 39.9 & 53.2 & 55.8 \\
\hline
\end{tabular}

Source: Ministry of Education EMIS Report, March 2008

Journal of Science and Technology ㄷN KNUST April 2010 
In summary the analysis seems to suggest that enrolment in JHS is rising for the three northern regions but still below the rest of the regions in the South.

\section{Analysis of senior high school enrolment}

Tables 5 and 6 report GER and NER data respectively for SHS students during the period under study. Data in Table 5 reveal that in general, the three northern regions had the lowest GER for the two academic years, 2006/07 and $2007 / 08$. In the $2006 / 07$ the figures were $22 \%$, $19.5 \%$ and $22.9 \%$ for Northern, Upper East and Upper West respectively. But, in addition to the three northern regions, Greater Accra also had a figure $(20.9 \%)$ lower than the Northern and
Upper West regions. Figures in 2007/08 follow the same trend, for the total, male and female students. The very low figures in the Greater Accra region might be due to large number of immigrants from the North and other regions to the capital. Majority of these immigrants might be from low socio-economic backgrounds and thus could not have easy access to senior high education. The Central and Eastern regions seem to be having the largest GER figures for the period and for both male and female.

Table 6 indicates that in general there has not been much improvement in NER for all regions during the two years for which we have data. Concerning female figures, Central region had a decline from $19.7 \%$ in $2006 / 07$ to $16.8 \%$ in

Table 5: Gross Enrolment Rate, SHS

\begin{tabular}{lcccccc}
\hline \multirow{2}{*}{ REGION } & \multicolumn{2}{c}{ TOTAL (GER in \%) } & \multicolumn{2}{c}{ MALE (GER in \%) } & \multicolumn{2}{c}{ FEMALE (GER in \%) } \\
& $\mathbf{2 0 0 6 / 0 7}$ & $\mathbf{2 0 0 7 / 0 8}$ & $\mathbf{2 0 0 6 / 0 7}$ & $\mathbf{2 0 0 7 / 0 8}$ & $\mathbf{2 0 0 6 / 0 7}$ & $\mathbf{2 0 0 7 / 0 8}$ \\
\hline Ashanti & 36.6 & 37.8 & 40.3 & 41.8 & 33.0 & 33.9 \\
Brong Ahafo & 27.6 & 28.8 & 30.4 & 31.9 & 24.5 & 25.4 \\
Central & 46.1 & 43.2 & 46.4 & 45.4 & 45.8 & 40.8 \\
Eastern & 45.1 & 45.6 & 45.2 & 45.5 & 44.9 & 45.7 \\
Greater Accra & 20.9 & 21.0 & 24.7 & 24.4 & 17.5 & 17.9 \\
Northern & 22.0 & 22.8 & 27.0 & 27.9 & 15.8 & 16.5 \\
Upper East & 19.5 & 19.6 & 21.8 & 22 & 16.8 & 16.8 \\
Upper West & 22.9 & 23.7 & 28.0 & 28.5 & 17.3 & 18.2 \\
Volta & 26.6 & 32.2 & 29.1 & 34.7 & 23.9 & 29.4 \\
Western & 24.1 & 24.9 & 26.0 & 26.8 & 22.1 & 22.8 \\
\hline
\end{tabular}

Source: Ministry of Education EMIS Report, March 2008

Table 6: Net Enrolment Rate, SHS

\begin{tabular}{lccrrrr}
\hline \multirow{2}{*}{ REGION } & \multicolumn{2}{c}{ TOTAL (NER in \%) } & \multicolumn{2}{c}{ MALE } & (NER in \%) & \multicolumn{2}{c}{ FEMALE (NER in \%) } \\
& $\mathbf{2 0 0 6 / 0 7}$ & $\mathbf{2 0 0 7 / 0 8}$ & $\mathbf{2 0 0 6 / 0 7}$ & $\mathbf{2 0 0 7 / 0 8}$ & $\mathbf{2 0 0 6 / 0 7}$ & $\mathbf{2 0 0 7 / 0 8}$ \\
\hline Ashanti & 13.3 & 14.1 & 13.9 & 15.1 & 12.6 & 13.1 \\
Brong Ahafo & 8.7 & 9.1 & 9.4 & 9.8 & 7.9 & 8.2 \\
Central & 18.5 & 17.2 & 17.5 & 17.5 & 19.7 & 16.8 \\
Eastern & 16.6 & 18.6 & 15.3 & 17.6 & 18.1 & 19.6 \\
Greater Accra & 7.7 & 8.4 & 8.8 & 9.3 & 6.7 & 7.6 \\
Northern & 6.2 & 6.4 & 7.1 & 7.5 & 5.0 & 5.1 \\
Upper East & 6.6 & 6.8 & 7.0 & 7.3 & 6.2 & 6.2 \\
Upper West & 5.3 & 7.6 & 5.9 & 9.0 & 4.5 & 6.0 \\
Volta & 7.8 & 10.9 & 7.7 & 10.8 & 8.0 & 10.9 \\
Western & 8.7 & 8.7 & 8.8 & 8.9 & 8.5 & 8.5 \\
\hline
\end{tabular}

Source: Ministry of Education EMIS Report, March 2008 


\section{Yusif and Yussof}

2007/08. In the case of male students Upper West and Volta recorded some significant increase from $5.9 \%$ and $7.7 \%$ respectively in $2006 / 07$ to $9 \%$ and $10.8 \%$ in $2007 / 08$ respectively. Indeed, NER for SHS does not seem to have a regular pattern. What is obvious is that the three northern regions and Greater Accra have the lowest figures for the two years. In the 2007/08 academic year Northern region had the lowest NER of $5.1 \%$ while Eastern region had the highest of $19.6 \%$.

Based on the analysis above, it is obvious that at the primary level the three northern regions have made significant improvement in enrolment since 2000 and there does not seem to be much difference between all the regions in the country. Average GER figure for the three regions in the North, at the JHS level, increased significantly from $41 \%$ in $2006 / 07$ to $67.4 \%$ in $2007 / 08$. NER which averaged $14 \%$ in $2006 / 07$ also increased to $42.3 \%$ in $2007 / 08$. Despite this improvement in enrolment figures, the North still lag behind the South in terms of enrolment at the JHS level. At the SHS level, apart from Upper West and Volta regions which recorded some significant increase in their GER, the rest had marginal increases in GER while the Central region rather had a decrease. Just like the JHS, the North has lower enrolment figures than the South at SHS level.

\section{Estimation of Education Gini Coefficient}

Indeed, studies regarding disparities in education performance among regions and districts in Ghana have been limited to a large extent to enrolment ratios, literacy rates, completion rate, schooling cohort survival rates, drop-out rates, gender parity index and test scores of core subjects - English language, Mathematics and Integrated Science. But, these indicators do not fully reflect the stock of a country's human capital and also enrolment ratios measure only people's access to education but do not show the cumulated educational attainment (Thomas et al., 2001). Consequently, in addition to enrolments' trend analysis, this paper measures the education Gini coefficient. The education Gini index is a new indicator for the distribu- tion of human capital and welfare. It measures the relative inequality of schooling distribution (Thomas et al., 2001). Its estimation in this section is to facilitate and provide further examination of educational inequality, within the regions of Ghana in recent years.

It appears that only Appiah-Kubi (2003) has used Gini coefficients to measure education inequality for Ghana. However, Appiah-Kubi uses educational attainments data of Ghanaian population above 14 years. This study captures the Ghanaian population below 18 years. Again, it is the first to estimate the country's education Gini coefficients at the regional level. Post-secondary education has been excluded due to scarcity of reliable data.

The measurement of the education Gini coefficients is based on two sources of data. First, is data from the Education Management Information System (EMIS) report of the Ministry of Education, March, 2008. Second, is data from the Ghana Living Standards Survey (GLSS), the fifth round, 2008. The GLSS is a multipurpose survey of households which collects data on education, health, employment and other living conditions of residents in Ghana. The proportion of the target population with the selected levels of schooling (primary, JHS and SHS) are then computed from the two data-sets covering the academic years 2005/2006, 2006/2007 and 2007/2008.

Concerning the years of schooling at the various levels of education selected, the study followed the Dzobo Committee report (2003) which is the basis of the current education system: 6 years primary, 3 years JHS, 3 years SHS and 4 years in university. For simplicity of computation the study assumed no years for pre -primary education. In fact, the Dzobo report did not provide years for this level. These reasons partially explain why pre-primary education was not analyzed in the previous sections. Therefore, in equation $2, \mathrm{y}_{1}=0$.

Education Gini coefficients can be calculated using enrollment and financial data. However, to properly measure education inequality, the Gini index should be based on educational at- 
tainment data (Thomas et al., 2001). Recent empirical studies have also used educational attainment data (Appiah-Kubi, 2003; Asriani, 2003; Mesa, 2007). Hence, this paper uses attainment data for estimation of the Education Gini coefficients.

There are two methods for calculating the education Gini coefficient. These are the direct method, associated with Deaton (1997) and the indirect method. This paper follows Thomas et al. (2001), and the education Gini coefficient is empirically estimated using the equation (indirect method).

$E_{L}=\left(\frac{1}{\mu}\right) \sum_{i=2}^{n} \sum_{j=1}^{i-1} P_{i}\left[y_{i}-y_{j} \boldsymbol{p}_{j}\right.$

Where, $E_{L}$ is the education Gini Coefficient, $\mu$ is the average years of schooling, $\mathrm{P}_{\mathrm{i}}$ and $\mathrm{P}_{\mathrm{j}}$ are the proportions of the population with the selected levels of schooling; $y_{i}$ and $y_{j}$ are the cumulative years of schooling at the different attainment levels and $\mathrm{n}$ is the number of levels..

Equation (1) is expanded to obtain the detailed summation process as

$E_{L}=\left(\frac{1}{\mu}\right) \boldsymbol{P}_{2}\left|y_{2}-y_{1}\right| P_{1}+P_{3}\left|y_{3}-y_{1}\right| P_{1}+P_{3} \mid y_{3}$

$\left.-y_{2}\left|P_{2}+P_{4}\right| y_{4}-y_{1}\left|P_{1}+P_{4}\right| y_{4}-y_{2}\left|P_{2}+P_{4}\right| y_{4}-y_{3} \mid P_{3}\right]$

The average years of schooling for estimation purposes, $\mu$, is also calculated using the formula

$\mu=\sum_{i=1}^{n} P_{i} y_{i}$

Table 7 shows results for boys, girls and the total. In all three years $(2005 / 06,2006 / 07$ and $2007 / 08)$ the estimates are lower for boys $(0.2924,0.2924$ and 0.3085$)$ than girls $(0.3086$, 0.3035 and 0.3129 ). This suggests that boys have comparatively lower inequality than girls in Ghana. But, a critical look at the boys' estimates show that from $2005 / 06$ to $2007 / 08$ ine-
Table 7: Trends in Education Inequality in Ghana - Primary, JHS and SHS Levels

GINI COEFFICIENT

\begin{tabular}{lccc}
\hline & $\mathbf{2 0 0 5 / 0 6}$ & $\mathbf{2 0 0 6 / 0 7}$ & $\mathbf{2 0 0 7 / 0 8}$ \\
Boys & 0.2924 & 0.2924 & 0.3085 \\
Girls & 0.3086 & 0.3035 & 0.3129 \\
Total & 0.3035 & 0.3076 & 0.3076 \\
\hline
\end{tabular}

Source: Author's computation using data extracted from GLSS5 (2008) and EMIS report (2008)

quality has worsened as the coefficient increased from 0.2924 in $2005 / 06$ to 0.3085 in $2007 / 08$. In the case of girls, the results indicate that inequality declined marginally from 0.3086 in $2005 / 06$ to 0.3035 in $2006 / 07$ but worsened between 2006/07 and 2007/08 (0.3129). The seemingly stagnating trends in inequality during the period under study not withstanding, education distribution in Ghana seems to have improved significantly since 2000 for teenagers. In the 1987/88, 1991/92, 1992/93 and 1998/99 academic years, education Gini coefficients for people aged 14 years and above for both males and females in Ghana were estimated to be $0.5863,0.5647,0.5378$ and 0.4745 respectively (Appiah-Kubi, 2003).

Table 8 presents education Gini coefficients for the ten regions in Ghana. Greater Accra is the only region where female education Gini coefficient $(0.2613)$ is marginally lower than male (0.2694). This seems to suggest that for the population below 18 years in the region, human capital is equally distributed among males and females. In the other regions, male education Gini coefficient is less than females and thus suggesting that for the population of interest, male human capital accumulation is higher than females.

Table 8 reveals that apart from the Greater Accra region, the three northern regions in the country, i.e. Northern, Upper East and Upper West regions had very low education Gini coefficients of 0.2961 for Northern, 0.2606 for Up- 


\section{Yusif and Yussof}

per East and 0.2712 for the Upper West. These low rates of Gini coefficients compared with the relatively higher ones for Ashanti (0.2993), Brong Ahafo (0.3450), Central (0.3168), Eastern (0.3085), Volta (0.3147) and Western $(0.3259)$ do not imply enrolment rates, drop-out rates, test score performance in English language, mathematics and science, quality of education etc are better in the three northern regions than the others. It rather means that in the North there seems to be more equitable distribution of education than the other regions. This makes sense because educational development in the North has experienced dramatic improvement between the periods 2005 and 2009, especially at the primary school level. This appears to explain the relatively low education Gini coefficient in that locality and thus confirming that moving any person out of illiteracy improves the level of education attainment (Thomas et al., 2001).

Again, a large number of the poor and illiterate population and their children from the North, migrate to the regions in the South. For example of the $3,154,860$ people in the Ashanti region, non-Akans number 591,377, constituting $18.7 \%$ compared with 27,713 non-Northerners who form $5 \%$ of the 548,807 people in the Upper West region (Ghana Statistical Service, 2005). Majority of the $5 \%$ is likely to be educated public servants.
The significance of the redistribution of population in Ghana is that the number of low socioeconomic status people in the South is increasing. Since education might not be the priority for the immigrants, this could have negative implications on equity issues in the South. Indeed, family level characteristics can fully account for differences in the levels of enrollment and educational attainments (Kirdar, 2007; Leibowitz, 1974).

In summary, it appears that the significant achievements in attaining some fairness in education in Ghana have been due to education policies initiated within the last two decades. These include the Free Compulsory Universal Basic Education (FCUBE), establishment of the Ghana Education Trust Fund (GETFund), the capitation grant, the school feeding programme, the cost sharing concept, etc. In addition, the significant achievement in good governance and the seemingly equitable distribution of public education expenditure per level might have also accounted for this. In 2005, public education expenditure was distributed as follows: $5 \%$ for pre-primary, $34 \%$ for primary, $42 \%$ for secondary and $18 \%$ for tertiary.

Undoubtedly, most of these policies derive from the Millennium Development Goals (MDGs). The MDGS are eight set of goals contained in the Millennium Declaration adopted

Table 8: Education Inequity by Region and Sex (2007/2008)

\begin{tabular}{lccc}
\hline \multirow{2}{*}{ Region } & \multicolumn{3}{c}{ EDUCATION GINI COEFFICIENT } \\
& Total & Male & Female \\
\hline Ashanti & 0.2993 & 0.3175 & 0.3319 \\
Brong Ahafo & 0.3450 & 0.3380 & 0.3560 \\
Central & 0.3168 & 0.3105 & 0.3205 \\
Eastern & 0.3085 & 0.3068 & 0.3124 \\
Gt. Accra & 0.2667 & 0.2694 & 0.2613 \\
Northern & 0.2961 & 0.2905 & 0.3026 \\
Upper East & 0.2606 & 0.2533 & 0.2678 \\
Upper West & 0.2712 & 0.2706 & 0.2714 \\
Volta & 0.3147 & 0.3088 & 0.3223 \\
Western & 0.3259 & 0.3286 & 0.3317 \\
\hline
\end{tabular}

Source: Author's computation using data extracted from GLSS5 (2008) and EMIS report (2008) 
by 189 nations, including Ghana, in September, 2000. It appears the government of Ghana ensures that national priorities are linked to these goals (eradicate extreme poverty and hunger, achieve universal primary education, promote gender equality and empower women, reduce child mortality, improve maternal health, combat HIV/AIDS, malaria and other diseases, ensure environmental sustainability and develop a global partnership for development).

\section{CONCLUSION}

In this paper trends in enrolments at the primary, JHS and SHS levels were analyzed. The assessment of the equity situation is that there seem to be improvement in enrolment at all levels. The enrolment gap between the North and the South appears to have been bridged at the primary level. In the 2007/2008 academic year average GER figure for the North was $95.7 \%$ compared with $95.8 \%$ for the South. At the JHS and SHS level there is an improvement in enrolment but the gap between the North and South still persist. In the North, GER figures for JHS and SHS are $67.4 \%$ and $22 \%$ respectively compared with $81.2 \%$ and $33.3 \%$ for the South.

Some important policy implications emerge from the discussions. The capitation grant policy and school feeding policy are some measures taken to reduce cost of schooling at the basic level. These policies seem to have been very successful at improving enrolment at that level. The feeding policy should be extended to cover as many schools as possible. The free uniform policy for basic school pupils, promised by the government, should be pursued vigorously and if possible extended to the secondary level. Consequently, cost of schooling could be reduced to allow many poor families in the rural areas, especially in the North to be able to send their children to school.

\section{REFERENCES}

Appiah-Kubi, K. (2003). Education Inequality in Ghana, MMAP Ghana Research Report No.1
Asriani, E. (2003). Education Inequality in Indonesia: Gini Coefficient of Education. Center for Policy and Implementation Studies, Maret.

Atuahene, F. (2006). A Policy analysis of the financing of tertiary education institutions in Ghana: An assessment of the objectives and the impact of the Ghana Education Trust Fund. PhD Dissertation, Faculty of the College of Education of Ohio University.

Boyle, H.N., Seebaway, S.Z., Lansa, I., and Boukamhi, A. (2007). Islamic Education Sector Study, Ghana, Education Development Centre, Inc. USAID/GHANA

Brown, K. (2006). 'New' educational injustices in the 'new' South Africa: A call for justice in the form of vertical equity. Journal of Educational Administration, 44(5):509519

Deaton, A. (1997). The Analysis of Household Surveys: A Microeconomic Approach to

Development Policy. Johns Hopkins University Press, Baltimore and London.

Deininger, K. (2003). Does cost of schooling affect enrollment by the poor? Universal primary education in Uganda. Economics of Education Review. 22(3):291-305

Ghana Statistical Service (2005). 2000 Population and Housing Census in GhanaDemographic, Economic and Housing Characteristics.

Ghana Statistical Service (2007). Poverty Patterns and Trends in Ghana. GSS, Accra, Ghana

Ghana Statistical Service (2008). Ghana Living Standards Survey Reports of the Fifth Round (GLSS5), September, 2008.

Hilmer, M. J. (2001) Redistributive fee increases, net attendance costs, and the distribution of students at public universities. Economics of Education Review, 20(6):551 $-562$

Kirdar, M. (2007). Explaining Ethnic Dispari- 


\section{Yusif and Yussof}

ties in School Enrollment in Turkey. Unpublished.

Leibowitz, A. (1974). Home Investment in Children, Journal of Political Economy, 2 (11) :S111-131

Levin, H. M., Belfield, C., Muennig, P., and Rouse, C. (2007). The public returns to public educational investments in AfricanAmerican males. Economics of Education Review, 26(6):699-708

McWilliam, H.O.A and Kwamena-Po, M.A. (1975). The Development of Education in Ghana: An Outline, Longman Group Ltd, London.

Mehta, A. C. (2003). Can There Be Alternative Indicators of Enrolment: A Critical Review of Frequently Used Indicators. Paper presented at a Regional Workshop on Education Statistics, from $27^{\text {th }}$ April- $1^{\text {st }}$ May, 2003, New Delhi, India

Mesa, E. P. (2007). Measuring Education Inequality in the Philippines. Thesis submitted to the School of Economics, University of the Philippines.

Ministry of Education, Science and Sports (2008). Report on Basic Statistics and Planning Parameters for Basic Education in Ghana 2007/2008. EMIS Report, March, 2008.
Ministry of Education (2000). History of education. Obtained from http://www.ghana. edu.gh/present/policies.html, November 2004.

Schultz, P.T. (1999). Health and schooling investments in Africa. Journal of Economic Perspectives, 13(3):67-88.

Thomas, V., Wang, Y. and Fan, X. (2001). Measuring Education Inequality: Gini Coefficients of Education. Policy Research Working Paper 2525, The World Bank, Washington D.C.

Tsakloglou, P. and Cholezas, L. (2005). Education and Inequality in Greece. Discussion Paper, May, 2005, IZA, Germany.

Yusif, H.M. (2009). Asymmetry in Education Development and Achievements in GhanaThe Ethnic Dimension. Are There Lessons From Malaysia? Paper submitted to the Centre for Ethnic Relations Studies (KITA), UKM, Malaysia. 